Bài báo khoa học

\title{
Xây dựng chương trình khai thác và hiển thị số liệu định vị sét kết hợp số liệu thám không vô tuyến tại Phòng dự báo Đài khí tượng thủy văn khu vực Nam Bộ
}

\author{
Lê Đình Quyết ${ }^{1 *}$, Lê Thị Nguyên Thảo ${ }^{1}$, Vũ Diệu Hồng ${ }^{1}$ \\ ${ }^{1}$ Đài KTTV KV Nam Bộ; quyet.le74@gmail.com; youko4996@gmail.com; \\ vudieuhong15@gmail.com \\ * Tác giả liên hệ: quyet.le74@gmail.com; tel: 84-982238137
}

Ban Biên tập nhận bài: 13/09/2020; Ngày phản biện xong: 27/10/2020; Ngày đăng: $25 / 12 / 2020$

Tóm tắt: $\mathrm{Xu}$ thế ứng dụng tin học hóa và tự động hóa đang được ứng dụng mạnh mẽ trong ngành khí tượng thủy văn. Các chương trình xử lý, khai thác, hiển thị dữ liệu trên nền tảng GIS được phát triển mạnh và ngày càng hoàn thiện. Đồng thời kết hợp nhiều nguồn dữ liệu khác nhau một cách tự động hóa, thay thế các công đoạn thủ công truyền thống, dự báo viên sẽ dành nhiều thời gian cho công tác phân tích và dự báo nghiệp vụ hiệu quả hơn. Bài báo này trình bày phương pháp sử dụng ngôn ngữ lập trình Visual Studio 2019 để xây dựng chương trình tự động kết nối với nguồn số liệu sét và bán tự động thu nhận số liệu thám không vô tuyến tự động giải mã số liệu và kết nối cơ sở dữ liệu GIS với định dạng shp, xây dựng các modul thu nhận số liệu thám không vô tuyến (TKVT) tại TP. Hồ Chí Minh; modul thu nhận số liệu định vị sét từ thiết bi TD-350 của hãng Nexstorm; modul hiển thị chỉ số đặc trưng CAPE, CIN, SI, LI, SWEAT của số liệu TKVT; modul hiển thị tự động trên nền tảng GIS của số liệu định vị sét theo lớp bản đồ trực quan đến cấp quận/huyện cho TP. Hồ Chí Minh và các khu vực lân cận. Với mục tiêu khai thác số liệu từ thiết bị định vị sét Nexstorm kết hợp số liệu thám không vô tuyến, nghiên cứu xây dựng một công cụ kết nối hai nguồn số trên phục vụ các dụ báo viên, với nguồn số liệu sét sẽ được hiển thị chi tiết đến cấp quận/huyện, xã/phường.

Từ khóa: Úng dụng GIS; Cảnh báo sét cho TP. Hồ Chí Minh và các khu vực lân cận; Các chỉ số đặc trưng CAPE, CIN, SI, LI, SWEAT của số liệu TKVT.

\section{Mở đầu}

Đã có nhiều nghiên cứu trên thế giới về thiết bị đo sét, hệ thống cảnh báo sét, kèm theo là các phần mềm hiển thị, các công cụ tính toán nhằm xác định vùng tập trung có sét cũng như thời gian sắp xảy ra để thông tin kịp thời đến người dân. Tại Phần Lan hệ thống cảnh báo sét rất hoàn hảo, người ta lắp đặt rất nhiều các thiết bị cảm biến đo sét của hãng Vaisala như Newer modems-LS7001 và 7002, cảm biến sét toàn bộ TLS, cảm biến GLD 360, FMI, các thiết bị định vị quang học từ không gian, nên đã kịp thời phát hiện nhiều trường hợp sét xảy ra,đưa ra những cảnh báo sớm. Tại Singapore, tiêu chuẩn của hệ thống cảnh báo sét là dựa trên các trạm khí tượng NEA. Hệ thống cung cấp các cảnh báo sét chính xác và đáng tin cậy nhất mà không bị gián đoạn. Đây là hệ thống duy nhất được công nhận bởi Cơ quan xây dựng $(B C A)$ do độ tin cậy của nó cao. Hệ thống đã được sử dụng bởi hơn 200 trường và các viện của chính phủ. Hệ thống cảnh báo sét thường được sử dụng cho các khu vườn, khu liên hợp thể thao, sân chơi, công trường... Chẳng hạn thiết bị EN50536 có bán kính hoạt động khoảng $50 \mathrm{~km}$ có khả năng phát hiện cả sét âm (khi điện tích trái dấu gặp nhau giữa đám mây với mặt đất) hoặc sét dương 
(khi điện tích trái dấu gặp nhau giữa đám mây với đám mây). Công ty Flancơlin của Pháp đã chế tạo thành công hệ thống thiết bị cảnh báo sét. Hệ thống thiết bị này có thể đưa ra cảnh báo mấy giờ trước khi xuất hiện sét, phạm vi dự báo chính xác từ $1-3 \mathrm{~km}$. Hệ thống cảnh báo sét này dùng máy cảm biến có độ nhạy cảm đặc biệt để thăm dò quang điện từ sét phát sinh ra. hệ thống định vị sét quốc gia của Mỹ với 130 trạm với bộ cảm biến IMPACT (improved accuracy through combined Technology). Bộ cảm biến IMPACT sử dụng anten từ, anten điện cảm ứng với tần số thấp của tia sét. Sử dụng kỹ thuật định vị từ MDF (magnetic direction finding) và thời gian tới TOA (time of arrival). Tín hiệu thu được biểu diễn theo thời gian của biến đổi trường do dòng sét gây nên. Với công cụ phân tích dạng sóng tìm điểm thời gian mà dòng đạt cực đại, có thể tính chính xác góc tới của tia sét. Tín hiệu được truyền theo vệ tinh từ các bộ cảm biến đến bộ xử lý trung tâm. Ở bộ xử lý trung tâm tổng hợp các số liệu và xác định vị trí phóng điện chỉ sau 20-30 giây. Kết quả cho thấy hệ thống có thể định vị chính xác phóng điện tới $500 \mathrm{~m}$ hay xa hơn. Ngoài thông tin về vị trí còn có các thông số sét khác như biên độ, mật độ sét.

Tại Việt Nam, Viện Vật lý Địa cầu năm 2003 đã nghiên cứu lắp đặt mạng trạm định vị phóng điện sét gồm 8 trạm. Thiết bị dựa trên công nghệ thời gian tới và định hướng từ trường để xác định vị trị sét đánh xuống đất. Trên cơ sở kết hợp với các nguồn số liệu khác, các tác giả đã xây dựng bản đồ mật độ sét theo mạng lưới trạm định vị sét, phân vùng mật độ sét. Mới đây tại khu vực sân golf trong sân bay Tân Sơn Nhất đã trang bị thiết bị đo sét, với khả năng xác định sét có thể xảy ra thông qua bộ cảm biến đo điện trường, với phạm vi không gian trong bán kính $32 \mathrm{~km}$. Khi điện trường đạt ngưỡng cảnh báo, thiết bị sẽ kích hoạt còi hú để mọi người ở gần đó có thể nhanh chóng tìm nơi trú, tránh. Năm 2017 tỉnh Đồng Tháp với Đề án "Mua sắm, lắp đặt máy và các thiết bị kết nối trạm cảnh báo dông, sét và trạm tự ghi mực nước bằng phương pháp không dây" trong dự án "Đề án Phòng, chống sét đánh trên địa bàn tỉnh Đồng Tháp đến năm 2020 ", tỉnh đã đầu tư lắp đặt 08 trạm báo sét, một trong những mục tiêu chính đó là báo động nhanh cho những bà con đang làm ngoài đồng ruộng khi có sét xảy ra.

Đài Khí tượng Thủy văn khu vực Nam Bộ thực hiện nhiệm vụ theo dõi phát hiện hiện tượng thời tiết nguy hiểm và cảnh báo như các hiện tượng dông, tố, lốc, mưa đá, sét... Nguồn số liệu sử dụng các nguồn số liệu các trạm KTTV bề mặt, vệ tinh, ra đa thời tiết Nhà Bè, thám không vô tuyến... Tuy nhiên công cụ để kết hợp nguồn số liệu thám không vô tuyến và các thiết bị cảm biến sét là chưa có. Thời gian vừa qua Ủy ban nhân dân thành phố Hồ Chí Minh đầu tư thiết bị TD-350 của hãng Nexstorm để ghi nhận số liệu định vị sét và giao Đài KTTV khu vực Nam Bộ quản lý, vận hành, khai thác dữ liệu, do đó nhu cầu cần có công cụ sử dụng số liệu từ thiết bị định vị sét Nexstorm kết hợp số liệu thám không vô tuyến cảnh báo sét cho thành phố Hồ Chí Minh và một số tỉnh lân cận.

\section{Phương pháp nghiên cứu}

\subsection{Giới thiệu khu vục nghiên cứu}

Thành phố Hồ Chí Minh có toạ độ $10^{\circ} 10^{\prime}-10^{\circ} 38^{\prime}$ Bắc và $106^{\circ} 22^{\prime}-106^{\circ} 54^{\prime}$ Đông, Nằm trong vùng chuyển tiếp giữa miền Đông Nam Bộ và đồng bằng sông Cửu Long, với diện tích $2.095,239 \mathrm{~km}^{2}$.

Nằm trong vùng nhiệt đới gió mùa cận xích đạo, nhiệt độ cao đều trong năm và có hai mùa mưa-khô rõ ràng. Mùa mưa từ tháng 5 đến tháng 11 , mùa khô từ tháng 12 đến tháng 4 năm sau. Lượng bức xạ dồi dào, trung bình khoảng $140 \mathrm{kcal} / \mathrm{cm}^{2} /$ năm. Số giờ nắng trung bình/tháng 160-270 giờ. Nhiệt độ không khí trung bình $27^{\circ} \mathrm{C}$. Nhiệt độ cao tuyệt đối $40^{\circ} \mathrm{C}$, nhiệt độ thấp tuyệt đối $13,8^{\circ} \mathrm{C}$. Lượng mưa cao, bình quân/năm $1.949 \mathrm{~mm}$. Năm cao nhất $2.718 \mathrm{~mm}$ (1908) và năm nhỏ nhất $1.392 \mathrm{~mm}$ (1958). Số ngày mưa trung bình/năm là 159 ngày. Khoảng $90 \%$ lượng mưa hàng năm tập trung vào các tháng mùa mưa từ tháng 5 đến tháng 11 . Độ ẩm tương đổi của không khí bình quân/năm $79,5 \%$; bình quân mùa mưa $80 \%$ và trị số cao tuyệt đối tới $100 \%$; bình quân mùa khô $74,5 \%$ và mức thấp tuyệt đối xuống tới $20 \%$. 
Về gió, chịu ảnh hưởng bởi hai hướng gió chính và chủ yếu là gió mùa Tây-Tây Nam và Bắc-Đông Bắc. Gió Tây-Tây Nam từ Ấn Độ Dương thổi vào trong mùa mưa. Gió Bắc-Đông Bắc từ biển Đông thổi vào trong mùa khô, khoảng từ tháng 11 đến tháng 2 . Ngoài ra có gió tín phong, hướng Nam-Đông Nam, khoảng từ tháng 3 đến tháng 5.

Trong quá trình phát triển và hội nhập, thành phố Hồ Chí Minh luôn khẳng định vai trò là một trung tâm kinh tế, tài chính, thương mại, dịch vụ của cả nước; là hạt nhân của vùng kinh tế trọng điểm phía Nam, một trong ba vùng kinh tế trọng điểm lớn nhất nước và cũng là vùng động lực cho công cuộc phát triển kinh tế-xã hội ở địa bàn Nam Bộ và cả nước theo chiến lược công nghiệp hoá, hiện đại hoá. Vì vậy, nhu cầu cảnh báo và dự báo phục vụ kinh tế-xã hội, an ninh-quốc phòng là rất lớn.

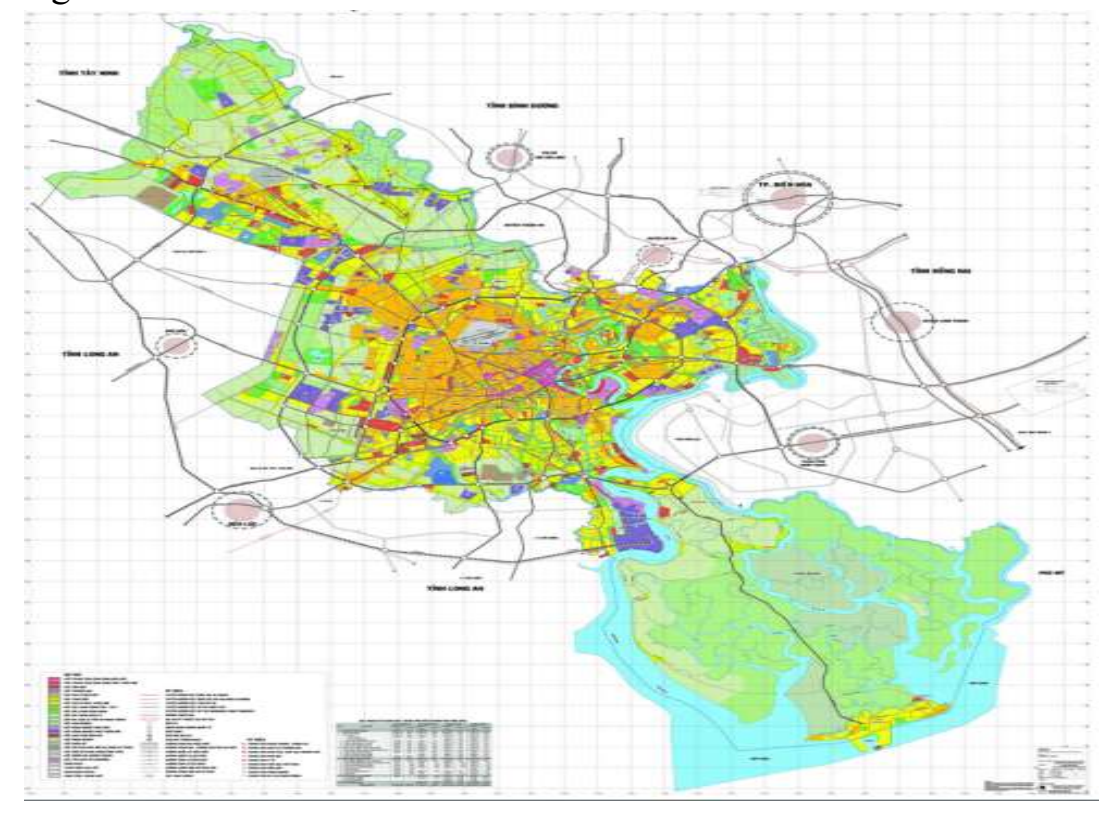

Hình 1. Bản đồ hành chính TP. Hồ Chí Minh.

\subsection{Xây dựng chương trình thu nhập dĩ liệu}

Với mục tiêu khai thác số liệu từ thiết bị định vị sét Nexstorm kết hợp số liệu thám không vô tuyến chúng tôi xây dựng một công cụ kết nối hai nguồn số trên phục vụ các dụ báo viên, với nguồn số liệu sét sẽ được hiển thị chi tiết đến cấp quận/huyện, xã/phường, nghiên cứu đã sử dụng phương pháp như sau:

- Sử dụng ngôn ngữ lập trình Visual Studio 2019 để xây dựng chương trình tự động kết nối với nguồn số liệu sét và bán tự động thu nhận số liệu thám không vô tuyến tự động giải mã số liệu và kết nối cơ sở dữ liệu GIS với định dạng shp.

- Số liệu thám không vô tuyến sau khi tính toán, lựa chọn, được thu nhận sẽ giải mã ra các chỉ số đặc trưng như CAPE, CIN, SI, LI, SWEAT. Sau đó các chỉ số này so sánh với chỉ số chuẩn đã được thống kê trong 5 năm gần đây, chương trình sẽ thống kê, tính toán và hiển thị các giá trị chênh lệch dễ dàng cho dự báo viên khai thác trực tiếp mà không phải thực hiện quá nhiều thao tác. Nguồn số liệu sét sau khi tự động thu nhận, giải mã hiển thị tự động trên chương trình, nguồn số liệu này sẽ được biểu diễn và chạy hiển thị theo thời gian trên nền GIS. Chương trình sẽ có các công cụ như phóng to, thu nhỏ, hiển thị ranh giới cấp tỉnh, quận/huyện hoặcđịa danh cũng như hiển thị chuyển động (loop) theo thời gian. 


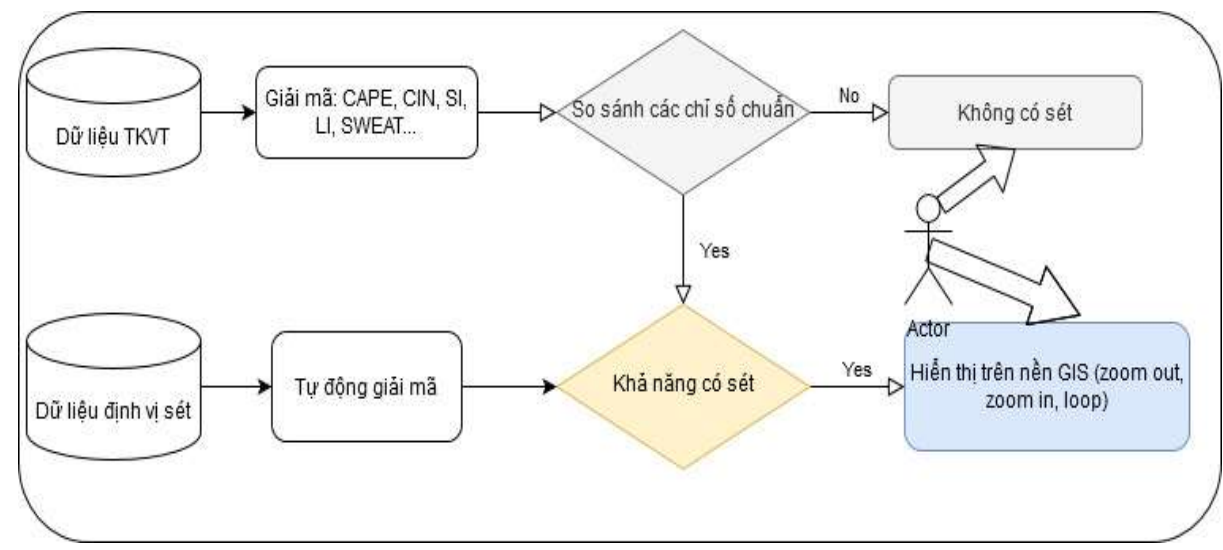

Hình 2. Sơ đồ khối chương trình công cụ khai thác và hiển thị số liệu định vị sét kết hợp số liệu thám không vô tuyến.

\subsection{Thu thập dĩu liệu}

Để tạo cơ sở dữ liệu, chương trình thu thập dữ liệu hàng ngày của trạm thám không vô tuyến TP. Hồ Chí Minh với mã trạm 48900, với tần suất ngày 2 lần. Nguồn số liệu từ thiết bị định vị sét Nexstorm với tần suất cập nhật 5 phút/ lần. Cuối cùng là nguồn số liệu GIS về địa danh và gianh giới đến cấp quận huyện.

\section{Kết quả nghiên cứu}

\subsection{Các hoạt động kỹ thuật chính để xây dung chuơng trình}

\subsubsection{Các nguồn dữ liệu đầu vào}

Đầu vào dữ liệu chương trình gồm 3 loại: những tham số đặc trưng đã chuẩn hóa trong 5 năm gần đây; số liệu thám không vô tuyến cập nhật theo ca quan trắc (ngày 2 lần); số liệu định vị sét sẽ cập nhật 5 phút/ lần.

Số liệu thám không vô tuyến sau khi kết thúc ca quan trắc, sẽ được mã hóa theo mã điện FM-35 TEMP theo chuẩn WMO và truyền tải đến các đơn vị khai thác, vì thế chương trình cần kết nối đến nơi lưu trữ mã điện đã chuẩn hóa này. Từ đây dữ liệu được tính toán theo các chỉ số đặc trưng của thám không vô tuyến như: CAPE, CIN, SI, LI, SWEAT.

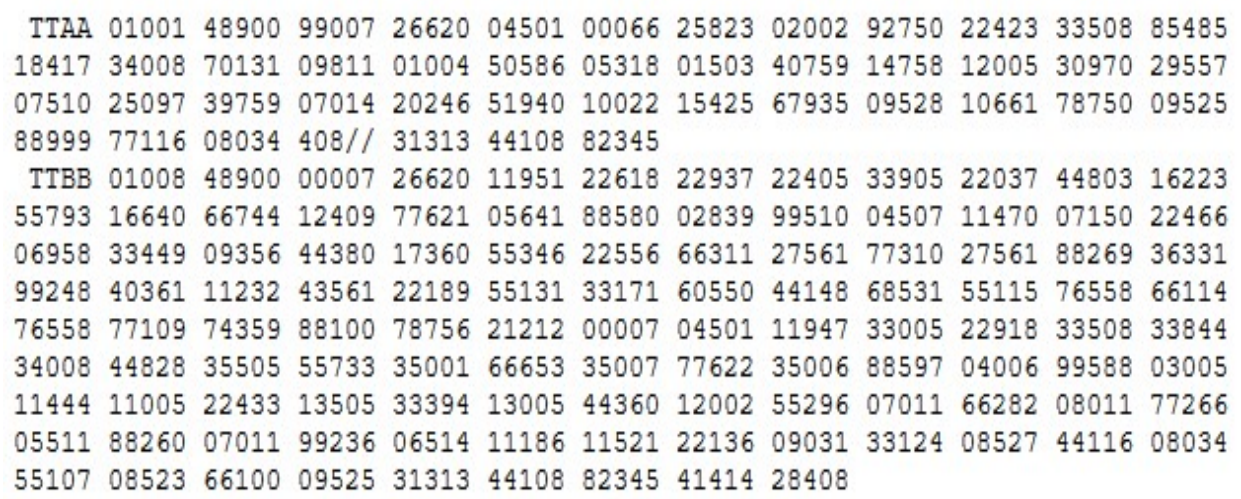

Hình 3. Số liệu thám không vô tuyến sau khi quan trắc và đã mã hóa theo FM-35 TEMP. Thiết bị Số liệu định vị sét thu thập từ thiết bị LD-350 của Nexstorm. 


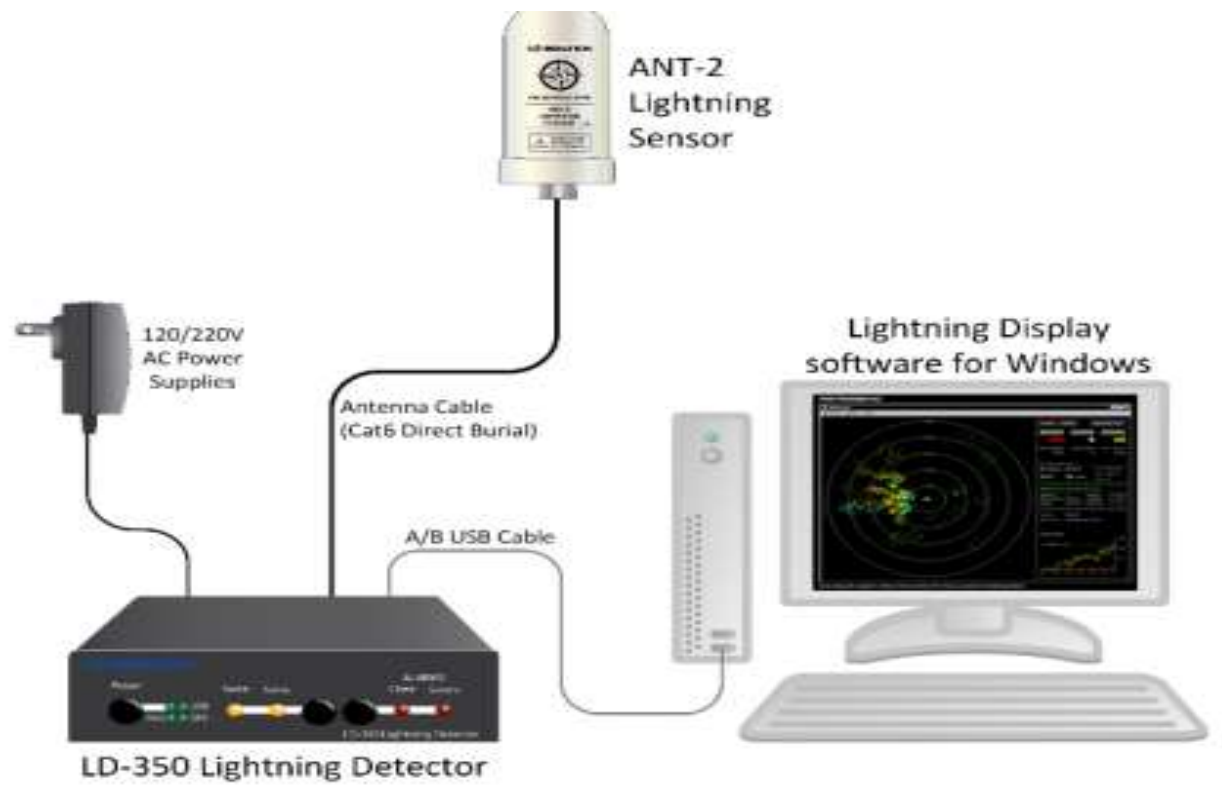

Hình 4. Sơ đồ mô phỏng thiết bị LD-350 của Nexstorm.

Dữ liệu thu nhận được trên thiết bị LD-350 lưu trên máy chuyên dụng sẽ được chương trình tự động tải về phục vụ khai thác.

\subsubsection{Xây dựng các modul kết nối dữ liệu.}

Modul nhập tham số đặc trưng đã chuẩn hóa trong 5 năm gần đây phục vụ tính toán so sánh với số liệu thám không vô tuyến được cập nhật hàng ngày. Modul kết nối thu nhận số liêu thám không vô tuyến được thiết lập bán tự động, sau khi kích hoạt có thể kết nối đến máy chủ lưu trữ và lựa chọn những ngày gần nhất để tải về và lưu trên thư mục trên máy khai thác.

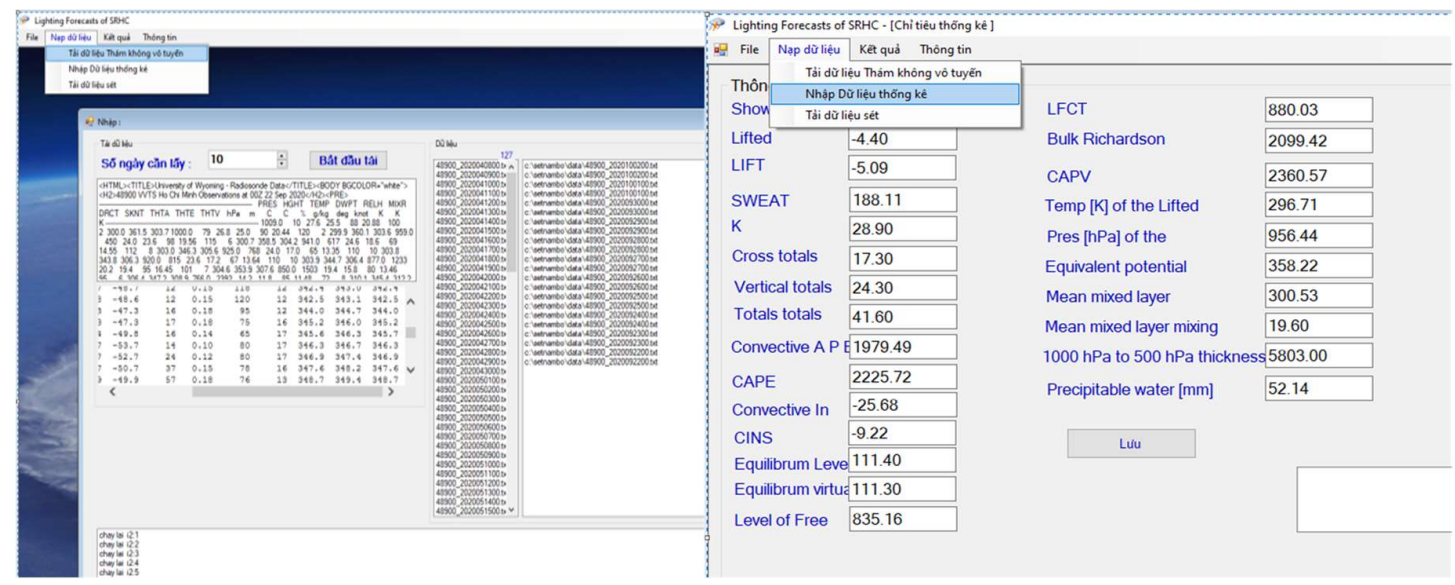

Hình 6. Modul nhập tham số đặc trung và modul tải dữ liệu của thám không vô tuyến.

Modul kết nối thu nhận số liêu định vị sét được thiết lập tự động, sau khi chương trình được kích hoạt và lưu trên thư mục trên máy khai thác. Với cách làm truyền thống hiện nay khi sử dụng phân tích các chỉ số đòi hỏi dự báo viên phải thực hiện thao tác tải bằng tay với nhiều bước như: nhập đường link máy chủ, nhập tên đăng nhập, nhập mật khẩu, lựa chọn tập dữ liệu, tải về máy tính lưu trữ, sử dụng các chương trình trung gian như RAOB để hiển thị. Sau khi sử dụng modul trên rõ ràng thao tác chỉ còn 2 bước, click chọn tải dữ liệu TKVT và hiển thị theo thời gian, giảm rất nhiều các bước trung gian. Bên cạnh đó, chương trình đã tính toán sẵn sự 
chênh lệch với các tham số chuẩn, sẽ dễ dàng cho dự báo viên biết được độ lớn của ca số liệu tăng cao hoặc ngược lại

\subsection{Xây dung phương trình dụ báo sét tù số liệu TKVT}

Nghiên cứu thử nghiệm phương pháp tham số trong dự báo sét bằng hàm phân lớp, sử dụng tổ hợp đặc trưng từ nhiệt độ, nhiệt độ điểm sương, nhiệt độ thế vị, nhiệt độ thế vị tương đương, độ ẩm tương đối tại các mực TKVT với các chỉ số SI, LI, KI, CAPE để tìm ra phương trình tổng hợp dự báo cho 5 chỉ số:

Đưa nguồn số liệu TKVT và kết hợp chương trình xây dựng phương trình để tìm ra phương trình dự báo như sau:

$$
\mathrm{Y}=0.00099 * \mathrm{CAPE}-0.00148 * \mathrm{CIN}-0.20604 * \mathrm{SI}-0.02568 * \mathrm{LI}-0.0029 * \mathrm{SWEAT}-0.25634
$$

\subsection{Kết quả của ưng dụng chương trình}

Sau khi dữ liệu được tải đầy đủ chương trình sẽ có modul hiển thị kết quả số liệu thám không vô tuyến và được tính toán so sánh với các tham số chuẩn, với kết quả đó sẽ dễ dàng cho dự báo viên khái quát những dấu hiệu đặc trưng và các nguy cơ xảy ra sét trên khu vực.

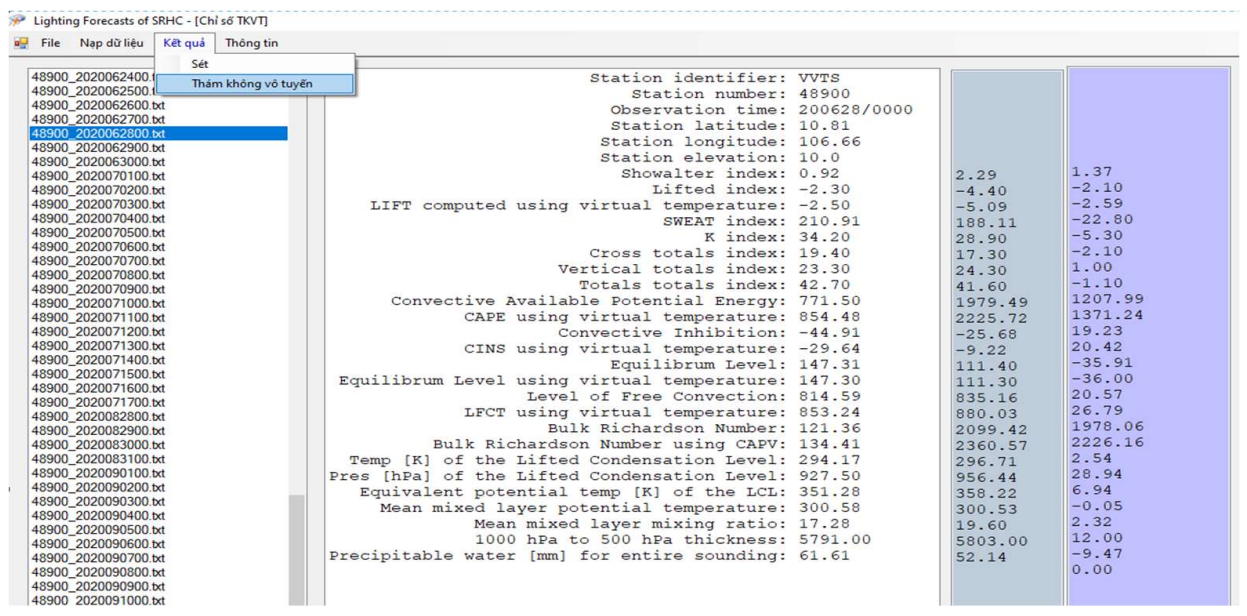

Hình 7. Kết quả số liệu thám không vô tuyến hàng ngày được tính toán và so sánh với tham số chuẩn (cột 1 thời gian, cột 2 tham số đã được chọn, cột 3: tham số chuẩn, cột 4: giá trị chênh lệch với tham số chuẩn).

Bên cạnh đó, chương trình đã tính toán sẵn sự chênh lệch với các tham số chuẩn, sẽ dễ dàng cho dự báo viên biết được độ lớn của ca số liệu tăng cao hoặc ngược lại. Trên cửa sổ khai thác số liệu định vị sét, hiển thị những số liệu mới nhất mà số liệu được cập nhật tự động, khi lựa chọn chức năng hiển thị chạy, số liệu sẽ biểu diễn liên tục trên nền GIS, với những tùy chọn hiển thị quận/huyện hoặc tỉnh, dự báo viên sẽ dễ dàng theo dõi diễn biến xuất hiện của sét theo không gian và thời gian, kết hợp kết thức chuyên môn khí tượng từ đó đưa những nhận định cảnh báo sét tới những khu vực có nguy cơ xảy ra hiện tượng sét. 


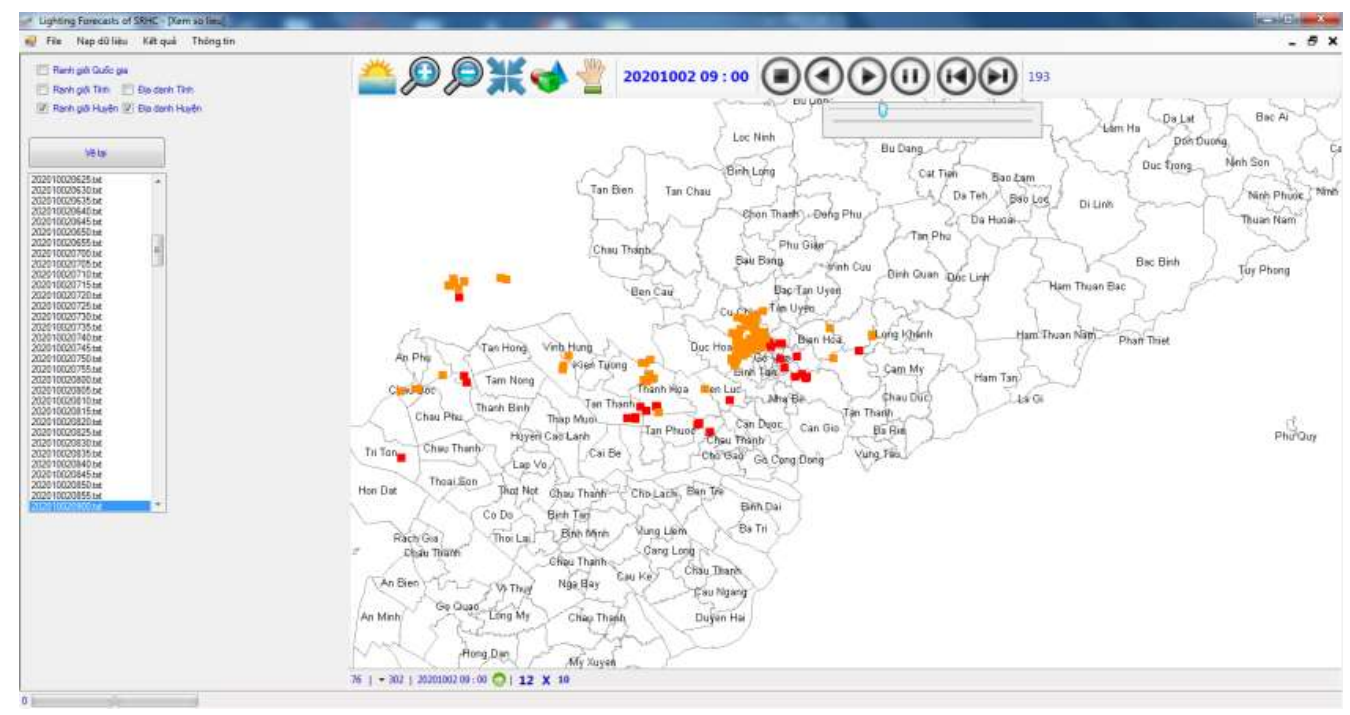

Hình 8. Kết quả số liệu định vị sét theo không gian và thời gian.

Trong trường hợp để chương trình chạy tự động, các modul sẽ tự chạy ngầm tải dữ liệu định vị sét và hiển thị tự động trên giao diện của chương trình, thuận tiện cho các dự báo viên tác nghiệp. So với trước năm 2019 việc xem nguồn số liệu định vị sét đã tiến một cách trực quan và nhanh chóng tức thời hơn, với các hình ảnh trước đây trên website http://promoser.amo.gov.vn thì chương trình đã có cập nhật hơn và chạy được trên nền GIS thay vì loop các ảnh gif với độ phân giải thấp và không có ranh giới địa danh quận huyện. Các thao tác zoom nhỏ hơn đến lớp phân giải địa lý chi tiết hơn.

\section{Kết luận}

Chương trình đã được thử nghiệp tại phòng dự báo Đài KTTV KV Nam bộ, bước đầu tự động hóa khai thác số liệu định vị sét và số liệu thám không vô tuyến. Dự báo viên tiết kiệm được rất nhiều thời gian, tập trung khai thác nghiệp vụ chuyên môn trên nển tảng phân tích dữ liệu kết hợp, hạn chế các thác tác thủ công truyền thống như trước kia.

Chương trình đã nhanh chóng khai thác được những nguồn dữ liệu mới nhất, nhanh nhất hiển thị trên nền tảng GIS, với kết quả hiển thị trực quan và sinh động.

Chương trình đã góp phần thử nghiệm tin học hóa, tiến dần đến công nghệ $4 \mathrm{G}$ và khẳng định xu thế tất yếu các công tác nghiệp vụ được hiện đại hóa theo chủ trương chung của toàn ngành xã hội nói chung và ngành khí tượng thủy văn nói riêng.

Đóng góp cho nghiên cứu: Xây dựng ý tưởng nghiên cứu: L.Đ.Q.; Lựa chọn phương pháp nghiên cứu: L.Đ.Q.; Xử lý số liệu: L.T.N.T., V.D.H.; Thu thập, phân tích, xử lý số liệu: L.T.N.T., V.D.H.; Xây dựng công cụ phần mềm thu thập, xử lý, tính toán, kết nối, hiển thị dữ liệu: L.Đ.Q., V.D.H.; Viết bản thảo bài báo: L.Đ.Q., L.T.N.T.; Chỉnh sửa bài báo: L.Đ.Q.

Lời cảm ơn: Tập thể tác giả trân trọng cảm ơn sự giúp đỡ cung cấp nguồn số liệu của Phòng Thông tin và Dữ liệu khí tượng thủy văn; Trạm thám không vô tuyến Tân Sơn Hòa, trân trọng cảm ơn đồng nghiệp Đài khí tượng Cao không, Lãnh đạo Phòng Dự báo KTTV khu vực Nam Bộ, Lãnh đạo Đài KTTV khu vực Nam Bộ đã tạo điều kiện để nhóm tác giả thực hiện nghiên cứu này.

Lò̀i cam đoan: Tập thể tác giả cam đoan bài báo này là công trình nghiên cứu của tập thể tác giả, chưa được công bố ở đâu, không được sao chép từ những nghiên cứu trước đây; không có sự tranh chấp lợi ích trong nhóm tác giả. 


\section{Tài liệu tham khảo}

1. Anh, N.X. Nghiên cứu xây dựng quy trình công nghệ phòng chống sét cho các công trình xây dựng ở Việt Nam. Viện Vật lý địa cầu, Viện Hàn lâm KH\&CN Việt Nam, 2013.

2. Cường, H.P. Quy trình theo dõi cảnh báo dông, sét và các hiện tượng thời tiết nguy hiểm kèm theo như tố, lốc, mưa đá, mưa lớn cục bộ, đề tài NCKH cấp Bộ: Nghiên cứu xây dựng hệ thống giám sát việc thực hiện quy trình dự báo và đánh giá chất lượng dự báo khí tượng thủy văn, cảnh báo thiên tai, mã số: TNMT.2016.05.18, 2017.

3. Lan, L.T.X. Báo cáo chuyên đề "Nghiên cứu đặc điểm khí hậu - khí tượng phục vụ nghiên cứu dông sét khu vực ba huyện Tân Biên, Tân Châu và Bến Cầu, tỉnh Tây Ninh”, Đài Khí tượng Thủy văn khu vực Nam Bộ, 2010.

4. Lan, L.X. Đặc điểm khí hậu và thủy văn thành phố Hồ Chí Minh, Đài Khí tượng Thủy văn khu vực Nam Bộ, thành phố Hồ Chí Minh. 2004.

5. Thanh, L.N. Báo cáo kết quả nghiên cứu khoa học - Đề tài Nghiên cứu nguyên nhân gây ra dông sét và đề xuất các giải pháp phòng tránh làm giảm nhẹ thiệt hại trong khu vực Tân Biên, Tân Châu và Bến Cầu, tỉnh Tây Ninh, Sở Khoa học và Công nghệ tỉnh Tây Ninh, Viện Địa lý Tài Nguyên TP. Hồ Chí Minh, 2010.

6. Tiến, T.T.; Dung, Đ.T.H. Nghiên cứu phương pháp dự báo dông cho sân bay Nội Bài theo trường khí tượng dự báo bằng mô hình ETA, Khoa học Đại học Quốc gia Hà Nội, Khoa học Tự Nhiên và Công nghệ 25, 2009.

7. Quyết định (dự thảo năm 2019, của Tổng cục Trưởng Tổng cục KTTV) Ban hành Hướng dẫn thực hiện Quy trình kỹ thuật và Quy định phân công trách nhiệm trong việc cảnh báo dông, sét, tố, lốc, mưa đá và mưa lớn cục bộ.

8. Junior, O.P.; Zepka, G.S.; Cardoso, I.; Saraiva, A.C.V. A 24-Hour Lightning Forecast System in Brazil. J. Aerosp. Technol. Manag. 2015, 7, 396-397.

9. Holle, R.L. Diurnal variations of NLDN cloud-to-ground lightning in the United States. Mon. Weather Rev. 2014, 142, 1037-1052.

10. Holle, R.L.; Brooks, W.A.; Cummins, K.L. Seasonal Lightning Distributions over North America. Proceeding of $24^{\text {th }}$ International Lightning Detection Conference \& $6^{\text {th }}$ International Lightning Meteorology Conference 18-21 April, San Diego, California, USA, 2016, 1-8.

11. Doswel, C.A. Short-range forecasting in Mesoscale Meteorology, Ed. P. Ray. Am. Met. Soc. Boston, Massachusets, 1986.

12. Charler, A. Rosenfeld. Severe Covective Storms-An Overview. Severe Convective Storm, A Meteorological Monograph. Am. Meteorol. Soc. 2001, 28, pp.71.

13. RAOB Version 5.4. The Complete Rawinsonde Observation Program. Use Guide and Technical Manual.

14. https://www.inspirentech.co/lightning-warning-system

15. http://toasystems.com/news/saving-lives-improving-thunderstorm-forecasting-mal aysia/

16. http://stormhighway.com/types.php

17. http://globalsailingweather.com/thunderstorms.php 


\title{
Writing a program for exploiting and displaying combined data of lightning detection and radiosonde sounding at forecast department of Southern Regional Hydro-meteorological Center
}

\author{
Le Dinh Quyet ${ }^{1}$, Le Thi Nguyen Thao ${ }^{1}$, Vu Dieu Hong ${ }^{1}$ \\ ${ }^{1}$ Southern Regional Hydrometeorological Center; quyet.le74@gmail.com; \\ youko4996@gmail.com; vudieuhong15@gmail.com
}

\begin{abstract}
In the modern world, applying computerization and automation in hydrometeorology has been widely used. Programs for processing, exploiting and displaying data on the Geographic Information System (GIS) have been strongly developed and more and more perfect. Also, combining automatically different data sources at the same time, replacing traditional manual methods so that forecasters could spend more time on analyzing and forecasting mission. This article presents the method of using the Visual Studio 2019 programming language to write a program which automatically connects to lightning data source and semi-automatically receives radiosonde sounding data. Also, it can automatically decodes data and connects GIS database with (.shp) format, builds modules to receive radiosonde sounding (RS) data in Ho Chi Minh City; modules to receive lightning detection data from TD-350 device of Nexstorm; modules to display the typical indicators of the RS data CAPE, CIN, SI, LI, SWEAT and modules that can automatically displays lightning detection data on GIS platform according to map layer in detail at district levels in Ho Chi Minh City and other areas nearby. With the aim of exploiting data from the Nexstorm lightning detection and the radiosonde souding data, we make a tool to connect the two above digital sources for forecasters, with lightning data will be displayed in detail at district, commune/ward levels.
\end{abstract}

Keywords: GIS application; Lightning warning for the Ho Chi Minh City and other nearby areas; The typical indicators of radiosonde souding data CAPE, CIN, SI, LI, SWEAT. 